$$
\begin{aligned}
& \text { COMPLIMENTARY COPN } \\
& \text { TECHNICAL INFOROM COMION } \\
& \text { DO NOT RETURM }
\end{aligned}
$$$$
\operatorname{Con} t-711008-7
$$

\title{
DEVELOPMENTS IN LOW-FLUX NEUTRON RADIOGRAPHY
}

\author{
AT BATTELLE-NORTHWEST (a)
}

\author{
K. L. Swinth
}

Battelle Memorial Institute

Pacific Northwest Laboratories

Richland, Washington 99352

October, 1971

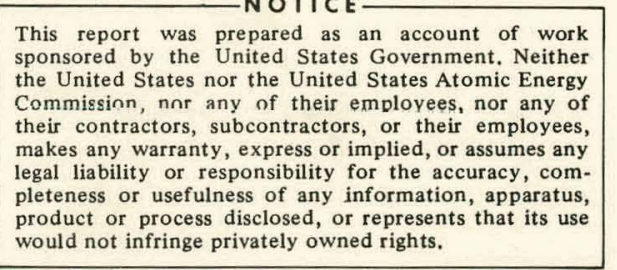

would not infringe privately owned rights.

(a)This paper is based on work performed under United States Atomic Energy Commission Contract AT(45-1)-1830. (Division of Isotopes Development). 


\section{DISCLAIMER}

This report was prepared as an account of work sponsored by an agency of the United States Government. Neither the United States Government nor any agency Thereof, nor any of their employees, makes any warranty, express or implied, or assumes any legal liability or responsibility for the accuracy, completeness, or usefulness of any information, apparatus, product, or process disclosed, or represents that its use would not infringe privately owned rights. Reference herein to any specific commercial product, process, or service by trade name, trademark, manufacturer, or otherwise does not necessarily constitute or imply its endorsement, recommendation, or favoring by the United States Government or any agency thereof. The views and opinions of authors expressed herein do not necessarily state or reflect those of the United States Government or any agency thereof. 


\section{DISCLAIMER}

Portions of this document may be illegible in electronic image products. Images are produced from the best available original document. 


\section{DEVELOPMENTS IN LOW-FLUX NEUTRON RADIOGRAPHY \\ AT BATTELLE-NORTHWEST*}

\section{K. L. Swinth}

\section{INTRODUCTION}

The use of isotopic sources for neutron radiography generally requires that imaging be performed in low fluxes of thermal neutrons $\left(\sim 5 \times 10^{3} \mathrm{n} / \mathrm{cm}^{2} \mathrm{sec}\right) .{ }^{(1)}$ To effectively utilize such low fluxes, one must optimize the source-collimator configruation ${ }^{(2)}$ and the imaging trechniques. Efforts at Battelle are directed toward utilization of ${ }^{252} \mathrm{Cf}$ in portable low-flux neutron radiography. The purpose of this paper is to present developments in both source holder-exposure facility design and in imaging techniques.

\footnotetext{
*This paper is based on work performed under United States Atomic Energy Commission Contract AT(45-1)-1830. (Division of Isotopes Development).
} 
Neutron radiography has seen a rapid growth in recent years because of its recognition as a nondestructive testing technique. Examination of low $Z$ materials which show poor $X$ or gamma contrast, or penetration of high $Z$ materials which heavily attenuate photons, but are penetrated by neutrons are two general areas for neutron radiographic examinations. Examination of composites, rocket propellants, explosive devices, biological specimens, reactor fueis, materials containing hydrogenous compounds and hydriding of metals are examples of applications for neutron radiography.

Most neutron radiography is performed at a reactor facility; however, many examinations can be performed with a facility utilizing an isotopic source. The use of an isotopic source does not provide the contrast, speed, or resolution obtainable with a reactor, but cost and portability are factors favoring isotopic sources. For example, when high reliability is required, it is desireable to verify the placement of gaskets or spacers and this may be needed on non-portable devices. Because of the high specific activity and low cost ${ }^{(3)}$ of ${ }^{252} \mathrm{Cf}$, it is a prime candidate for neutron radiography. Predictions are that the cost will be reduced even more in the future thus increasing the application of ${ }^{252} \mathrm{Cf}$ as a source of neutrons.

\section{EXPOSURE FACILITIES}

In order to utilize isotopic sources for thermal-neutron radiography one must have a means of moderating the source neutrons and a means of extracting a beam of thermalized neutrons. The same 
facility is generally expected to provide the necessary radiation shielding. This implies a fairly massive shield and a means of blocking the thermal neutron beam during film changes. Three such facilities have been developed at Battelle for use with isotopic neutron sources, specifically ${ }^{252} \mathrm{Cf}$.

Since neutron radiography requires extraction of a beam of neutrons from the exposure facility, one must provide a means of isolating this beam from occupied areas by shielding or distance during exposures. At Battelle all of our experiments are performed in an underground room originally designed for a high output neutron generator. This provides adequate shielding for occupied areas.

\section{Exposure Facility One (NC-1)}

The primary neutron radiographic device in use at Battelle is a portable unit weighing 350 ibs. $(4,5)$ This unit has been used extensively $(5,6)^{\circ}$ and was the primary too in the described investigations. Figure 1 shows a photograph of the egg shaped fiberglass shell ( $\sim 4 \mathrm{ft}^{3}$ ) which contains moderators and shielding materials surrounding a ${ }^{252} \mathrm{Cf}$ source. Figure 2 shows the internal arrangement of moderators and shielding materials. The selection of moderators was based on a computer-assisted analysis of various materials. (5) The unit was originally used with a $268 \mu \mathrm{gm}{ }^{252} \mathrm{Cf}$ source which has since decayed to approximately $150 \mu \mathrm{gm}$. The moderator and gamma filtration within the beam tube can be changed and this has an effect 
on both the flux and neutron to gamma ratio as shown in Table 1 .

Table 1: Effect of various moderators and gamma filters on the beam flux and gamma ratio

\begin{tabular}{|c|c|c|c|c|}
\hline Moderator & $\begin{array}{l}\text { Gamma }(1) \\
\text { Filter } \\
\end{array}$ & $\begin{array}{c}\text { Flux } \\
\left(\mathrm{n} / \mathrm{cm}^{2} \mathrm{sec}\right)\end{array}$ & $\begin{array}{c}\text { Neutron-Gamma } \\
\text { Ratio } \\
\left(\mathrm{n} / \mathrm{cm}^{2} / \mathrm{mR}\right) \\
\end{array}$ & $\begin{array}{l}\text { Cadmi um } \\
\text { Ratio (3) }\end{array}$ \\
\hline & . & & & \\
\hline None & None & 1.48 & 3.6 & 2.00 \\
\hline Paraffin & $P b-1$ & 1.43 & 5.15 & 2.60 \\
\hline Paraffin & $U-1$ & 27.4 & 6.28 & -- \\
\hline $\mathrm{Zr} \mathrm{H} 2$ & None & 1.19 & 5.95 & 2.32 \\
\hline $\mathrm{Zr} \mathrm{H} \mathrm{H}_{2}$ & $\mathrm{~Pb}-1$ & 0.941 & 5.46 & 2.0 \\
\hline $\mathrm{Zr} \mathrm{H}_{2}$ & $P b-2$ & 0.959 & 6.28 & 2.10 \\
\hline $\mathrm{Zr} \mathrm{H} 2$ & $U-1$ & 1.05 & 6.30 & 2.15 \\
\hline $\mathrm{Zr} \mathrm{H} \mathrm{H}_{2}$, & $U-2$ & 1,19 & 5.25 & 2.70 \\
\hline $\mathrm{Zr} \mathrm{H} 2$ & $U-1(2)$ & 1.22 & 7.30 & 2.43 \\
\hline $\mathrm{Ti} \mathrm{H} \mathrm{H}_{2}$ & None & 0.542 & 2.38 & 1.56 \\
\hline $\mathrm{Ti} \mathrm{H}$ & $\mathrm{Pb}-1$ & 0.562 & 2.80 & 1.65 \\
\hline
\end{tabular}

1) $\mathrm{Pb}-1=0.5 \mathrm{~cm} ; \mathrm{Pb}-2=1.0 \mathrm{~cm} ; U-1=0.32 \mathrm{~cm} ; \quad \mathrm{U}-2=0.64 \mathrm{~cm}$

2) Gamma filter on film side of moderator, others on source side

3) Ratio of bare indium response to cadmium covered response

All the neutron measurements were made with indium and cadmium covered indium foils. The statistical precision (standard deviation) was held to less than $3 \%$ and the accuracy of the foil-counter calibration is estimated to be $5 \%$. Gamma measurements were made with an air equivalent ionization chamber (Hanford C.P.).All measurements were made at $50 \mathrm{~cm}$ from the source with a cadmium tube used to exclude room scattered neutrons. 
It is evident from the table that Zirconium hydride with a depleted uranium filter on the film side would be the technique of choice for direct neutron radiography; however, for transfer radiographs one might prefer to dispense with the moderator and filter.

Figure 3 shows the measured fluxes at various distances with a paraffin moderator and a lead gamma filter. Included on the figure is the calculated geometrical unsharpness for a $1 \mathrm{~cm}$ thick object. This is included to emphasize that the problem is more than one of choosing an appropriate flux level.

Presently the surface dose rates around this facility (NC-1) are $150 \mathrm{mrem} / \mathrm{hr}$ neutron and $50 \mathrm{mr} / \mathrm{hr}$ gamma. These dose rates fall rapidly with distance and are $15 \mathrm{mrem} / \mathrm{hr}$ and $5 \mathrm{mr} / \mathrm{hr}$, respectively, at four feet.

This facility was used in most of the imaging experiments reported in this paper with a single depleted uranium gamma filter (0.185 inches) and a zirconium hydride moderator ( 1.8 1nches). A cadmi um collimator with a length to diameter ratio of about 8:1 was employed and the source to object distance was $69 \mathrm{~cm}$. At the image plane the thermal flux was $2.85 \times 10^{2} \mathrm{n} / \mathrm{cm}^{2} \mathrm{sec}$ with a cadmi um ratio of 1.45 . The neutron to gamma ratio was approximately $6.3 \times 10^{4}$ neutrons $/ \mathrm{cm}^{2} / \mathrm{mR}$. 
Exposure Facility Two (NC-2)

A second exposure facility has been built which has greater portability. This unit employs the same fiberglass shell used on the previously described facility; hovever, the unit is filled with water for moderation of the neutrons. This means that the facility can be put into position with only the weight of the shell and miscellaneous hardware ( 75 lbs). After positioning the unit is filled with water and the source positioned near the center. The unit will now weigh approximately 320 pounds. Figure 4 is a schematic representing the general features of the facility. An off-center source geometry is used to take advantage of the improved beam extraction offered by this technique. $(2,7)$ The collimator consists of a cadmium lined aluminum cone and is built into the unit; however, different collimators with different length to diameter ratios can be mounted in the system. To block the neutron beam the collimator is filled with water by a gravity feed system. Although this takes about 2 minutes, it is of little disadvantage with the low-fluxes employed and could be speeded with a pump.

For larger sources and fast imaging techniques, a pump would háve to be employed for filling and emptying the collimator along with an air jet to remove droplets from the interior of the exit window. 
The present collimator has a length to diameter ratio of 15:1 and the source to object distance is fixed at $38 \mathrm{~cm}$. At the front of the collimator the thermal flux is $9.4 \times 10^{2} \mathrm{n} / \mathrm{cm}^{2}-\mathrm{sec}$ with a cadmi um ratio of 1.8 and a neutron to gamma ratio of $4.2 \times 10^{4} \mathrm{n} / \mathrm{cm}^{2} / \mathrm{mR}$.

The surface dose rate with the $2150 \mu \mathrm{gm}{ }^{252} \mathrm{Cf}$ source in this unit is approximately $170 \mathrm{mrem} / \mathrm{hr}$ neutrons and $100-180 \mathrm{mR} / \mathrm{hr}$ of gamma. The dose rates drop to $18 \mathrm{mrem} / \mathrm{hr}$ neutrons and $8 \mathrm{mr} / \mathrm{hr}$ gamma at 5 feet. Higher dose rates are expected from this unit due to the absence of internal ganma shields and thermal neutron capture materials.

\section{Exposure Facility Three}

Unlike the other facilities the last facility is stationary and employs a large source $(1.7 \mathrm{mgm})$ of ${ }^{252} \mathrm{Cf}$. Figure 5 is a drawing of the facility which is basically a large water tank. The source can be positioncd at any level up to 18 inches above the surface of the water for exploration of beam extraction techniques. The unit is an extremely versatile source of neutrons. When the source is in the stored position the surface dose rates are $4 \mathrm{mrem} / \mathrm{hr}$ neutrons and $10 \mathrm{mr} / \mathrm{hr}$ gamma.

\section{DIRECT RADIOGRAPHY IN LOW-FLUX FIELDS}

Direct imaging (placing film and converter directly in beam) in low-flux beams can be performed satisfactorily with standard techniques such as gadolinium foils $(2,5,6)$ however, it is desirable to use the fastest techniques possible. A gadolinium (0.002 in.) foil with Kodak AA. film will take on the order of $100 \mathrm{hrs}$. to reach a radiographic' 
density of 1.5 and on the order of 20 hrs with Kodak No Screen or $R P / R$ film. This is in a thermal flux of about $2.85 \times 10^{2} \mathrm{n} / \mathrm{cm}^{2}-\mathrm{sec}$. Scintillators have greatly enhanced speed, but result in a loss of resolution.

Figure 6 shows the radiographic density obtained with various direct imaging techniques and various exposure times. A vacuum cassette was used on all the exposures and films were developed to manufacture's specifications. Although not as fast, the newer NE425 scintillator produces an image with better definition and is preferred.

The rare earth scintillator, gadolinium oxysulfide, was developed as an X-ray phosphor; however, because of its high content of gadolinium it was felt that it might prove useful for neutron radiography. ${ }^{(8)} \mathrm{Gd}_{2} \mathrm{O}_{2} \mathrm{~S}: \mathrm{Tb}$ has $i$ ts primary emission peaks above $4800 \AA$ suggesting that a green-sensitive film (Kodak Type 0 ) would be desirable. Most phosphors emit at blue wavelengths and are suited for use with blue-sensitive films. $\mathrm{Gd}_{2} \mathrm{O}_{2} \mathrm{~S}: \mathrm{Tb}$ does show improved sensitivity over Gd metal foils; however, the use with a blue-sensitive film unexpectedly shows (Figure 6) the greatest sensitivity. The $\mathrm{Gd}_{2} \mathrm{O}_{2} \mathrm{~S}: \mathrm{Tb}$ employed in these experiments consisted of about $24 \mathrm{in.}^{2}$ spread on a piece of mylar to a thickness of $125 \mu$. An improvement in gamma discrimination could be realized by decreasing the thickness of the phosphor to $25-50 \mu$. 
Figure 7 shows a drawing of the image quality indicator employed during the tests with the various imaging methods. A peice of cadmium with three series of holes decreasing in spacing was used to indicate resolution along with a step wedge to indicate unsharpness. The series of holes in the cadmium are .132, .069, and :034 inches in diameter with spacing decreasing from .125 to 0.002 inches. The step wedge consists of plastic strips $0.2,0.5$ and $1.0 \mathrm{~cm}$ high with cadmium strips mounted at each height and on the aluminum base.

Table 2 shows the radiographic contrasts achieved with various techniques. Increasing cadmium contrast indicates a better thermal image while increasing lead contrast illustrates a higher ratio of gamma to neutron imaging. The indium contrast is a measure of the epithermal neutron influence while the $\mathrm{CH}_{2}$ (plexiglass) gives a = measure of the contrast for a material which is a much weaker attenuator of neutrons than cadmium. 
Table 2: Contrast readings for IQI, with various converter-film combinations. The films were exposed to a radiographic density of about 1.5.

Imaging

Technique*

LiF-ZnS (NE421) $+R P / R$

LiF-ZnS (NE425) $+R P / R$

$\mathrm{Gd}_{2} \mathrm{O}_{2} \mathrm{~S}: \mathrm{Tb}+\mathrm{RP} / \mathrm{R}$

0.34

$\mathrm{Gd}_{2} \mathrm{O}_{2} \mathrm{~S}: \mathrm{Tb}+$ Type 0

0.23

Gd $(2 m i l s)+R P / R$

0.31

0.52

0.02

0.09

0.16

Contrast - Change in Film Density " $\Delta \mathrm{D}$ " Cd(0.5 mm) $\quad \mathrm{Pb}(1.15 \mathrm{~mm}) \quad \mathrm{CH}_{2}(1.5 \mathrm{~mm})$ In $(0.76 \mathrm{~mm})$

0.65

0.13

0.24

0.18

0.12

0.26

0.23

0.23

0.17

0.16

*Film designations are for Kodak radiographic films.

Figure 8 shows radiographs comparing LiF-ZnS scintillators with $R P / R$ film. The top radiograph is with the newer NE425 while the bottom radiograph was made with an NE421 scintillator. It is apparent that the ME425 has a more uniform response and better resolution. Note the absence of a significant response to the lead squares. Figure 9 shows radiographs made with both type 0 and type $\mathrm{RP} / \mathrm{R}$ film using a $\mathrm{Gd}_{2} \mathrm{O}_{2} \mathrm{~S}: \mathrm{Tb}$ scintillator. Both radiographs show 
excellent resolution. Figure 10 shows radiographs made with a 2 mil gadolinium foil and both $R P / R$ and $A A$ film. The resolution on figures 9 and 10 are comparable; however, it is obvious that the gadolinium metal foil techniques have a greater response to gamma.

Fiber optics face plates in conjunction with LiF-ZnS scintillators (NE421) were investigated for increasing the resolution of neutron radiographs. Figure 11 shows radiographs taken with just the scintillator and with two different face plates. A simple pressure cassette was used for the exposures and RP/R film was used for all the exposures. It was necessary to make exposures with the film behind the scintillator. This alone causes an increase of $30 \%$ in the exposure time necessary to reach the same optical density in comparison to an exposure using this scintịinator as a back screon.

An improvement in contrast andresolution is noticeable with the face plates although a loss of speed results. With the large area face plate it takes 1 1/2 times as long for a comparable density and practically 5 times as long with the small face plate. The smaller unit is thicker and has poorer transmission in the blue region. Improvement in resolution is not as great with the large area face plate and this may be due partly to the larger fiber size which is 10 microns as opposed to the approximately 5.5 microns of the smaller piece. 
The exact mechanism causing the improved resolution with the fiber optics is not entirely understood. The improved resolution may be due primarily to the increased contrast, but what causes the improved contrast is not fully understood unless direct alpha interactions with the film are important. The small fiber optics shows the best resolution and this may be due to the improved light collination by the smaller fibers on it may be due to better photon statistics from light attenuation.

\section{INDIRECT RADIOGRAPHY IN LOW-FLUX FIELDS}

Indirect neutron radiography is important since it is the only practical technique for eliminating gamma response on radiographs and for radiographic examination of irradiated materials. In general, fairly' high fluxes of neutrons are desirable for indirect radiography since the technique is limited by the activation and decay of an imaging foil. For indirect imaging with law fluxes one must utilize long half-life, high cross-section materials such as eurnpium.

The use of europium foils for indirect neutron imaging is being investigated ${ }^{(G)}$ to provide this technique for low-flux neutron radiography. Europium has a higher cross section, a higher natural abundance and a longer half-life than dysprosium and faint indirect images have been obtained in a flux of $3 \times 10^{2} \mathrm{n} / \mathrm{cm}^{2} \mathrm{sec}$. High contrast inages exhibit resolution comparable to dysprosium foils. 
The problem encountered with europium metal foils is the extreme instability of the metal in air. Upon exposure to air, the foils rapidly oxidize and form a loose powder. After trying a number of techniques, we have developed a successful method using metal foils handled in an inert atmosphere (nitrogen filled glove box) and exposed in a vacuum cassette. Previously ${ }^{(6)}$ foils of $\mathrm{Eu}_{2} \mathrm{O}_{3}$ were exposed and transferred in a vacuum cassette with storage in mineral oil; however, these foils are no longer available.

Table 3 summarizes results obtained with both europium and dysprosium foils in low fluxes. Exposures and transfers were done for 3 half lives. On some experiments a calcium tungstate (Cal04) screen was used to improve the exposure on the transfer film. Data from these experiments are also included in Table 3. Figure 12 shows a transfer neutron radiograph made with the europium foil. Exposure was in a flux of $7.8 \times 10^{2} \mathrm{n} / \mathrm{cm}^{2}-\mathrm{sec}$ for three half lives and an equal time was used for transfer to RP/R film sandwiched between the foil and a $\mathrm{CaWO}_{4}$ intensifying screen.

\section{CONCLUSIONS}

Other efforts are underway at Battelle on the development of imaging counters for low-resolution radiographic inspection. This work is part of the overall development of low-flux radiography techniques.

Although low-flux radiography has lower resolution and requires - longer exposure periods than radiography in high fluxes of thermal 
neutrons, it does make neutron radiography available to more people and makes available the possibility of portable neutron radiography. Development of imaging techniques and better exposure facilities as described in this paper, capitalizes on the low-fluxes available from isotopic sources. The resolution of a $\mathrm{Gd}_{2} \mathrm{O}_{2} \mathrm{~S}: \mathrm{Tb}$ scintillator is comparable to a gadolinium metal foil and promises a significant reduction in neutron exposure time. This technique will be investigated further with hopes of achieving a better neutron to gamma ratio with a thinner foil. Fiber optics face plates enhance the resolution and contrast of LiF-ZnS scintillators and could make the use of this technique much more acceptable. 


\section{REFERENCES}

1. J. P. Barton, "Foreseeable Application of ${ }^{252} \mathrm{Cf}$ to Neutron Radiography," Isotopes and Radiation Technology, Vol. 7, No. 3, (1970).

2. J. P. Barton and M. F. Klozar, "Californium-252 as a Neutron Radiography Source," Californium-252 Progress, 2, p. 20, (1971).

3. L. A. Heinrich, "Comparison of Neutron Source Costs, "Proceedings of the American Nuclear Society National Topical Meeting on Neutron Sources and Applications, Apri1 19-21, 1971, USAEC Report CONF-710402, Vo1. II, P. I-142, (1971).

4. J. L. Cason, "Design and Fabrication of a Portable Device for Neutron Radiography." Pacific Northwest Laboratory, BNWL-1329, March 1971.

5. C. B. Shaw and J. L. Cason, "Portable Neutron Radiographic Camera Using Californium-252", Materials Evaluation, 29, 40 (February, 1971).

6. J. L. Cason and C. B. Shaw, "Some NDT Applications Using Cf-252," 1970 Fall Conference of the American Society for Nondestructive Testing, Cleveland, Ohio (October, 1970).

7. K. D. Kok and J.W. Ray, "Optimization of Source-Collimator Geometry for a Neutron Radiographic Facility Utilizing a ${ }^{252}$ Cf Source," Proceedings of the American Nuclear Society National Topical Heeting on Neutron Sources and Applications, Apri1 19-21, 1971 USAEC Report CONF-710402, Vol. III, P. IV-47, (1971). 


\section{REFERENCES (Cont'd)}

8. K. A. Wichersheim, R. V. Alves and R. A. Buchanan, "Rare Earth Oxysulfide X-ray Phosphors." IEEE Transactions on Nuclear Science, NS-17, Pg. 57 (1970).

9. Personal Communication, R. A. Buchanan, Lockheed Research Laboratory, Palo Alto, California. 
Table 3: Indirect Imaging in Low-Flux Neutron Fields.

\begin{tabular}{|c|c|c|c|}
\hline Imaging Tes & (F.iTm) & $\begin{array}{c}\text { Flux } \\
\left(\mathrm{n} / \mathrm{cm}^{2}-\mathrm{sec}\right)\end{array}$ & $\begin{array}{l}\text { Radiograph } \\
\text { Density }\end{array}$ \\
\hline $\mathrm{Eu}+\mathrm{CaWO}_{4}$ & $(R P / R)$ & $7.8 \times 10^{2}$ & 0.385 \\
\hline $\mathrm{Eu}+\mathrm{CaWO}_{4}$ & $(R P / R)$ & $2.85 \times 10^{2}$ & 0.335 \\
\hline Eu & $(\mathrm{RP} / \mathrm{R})$ & $2.85 \times 10^{2}$ & 0.242 \\
\hline Eu & $(A A)$ & $10^{4}$ & 1.42 \\
\hline $\mathrm{Dy}+\mathrm{CaWO}_{4}$ & (RB) & $10^{4}$ & 1.175 \\
\hline Dy & $(R P / R)$ & $1.26 \times 10^{3}$ & 0.172 \\
\hline $\mathrm{Dy}+\mathrm{CaHO}_{4}$ & $\cdot(R P / R)$ & $1: 26 \times 10^{3}$ & 0.240 \\
\hline
\end{tabular}


FIGURE CAPTIONS

Figure 1: Photograph of neutron exposure facility (NC-1) on its portable stand.

Figure 2: $\quad$ Cutaway drawing showing approximate arrangement of moderators and shielding in $\mathrm{NC}-1$.

Figure 3: $\quad$ Thermal flux and calculated geometrical unsharpness for the radiography beam from NC-1. Operaton with a paraffin moderator and 0.1 in lead gamma filter.

Figure 4: $\quad$ Sketch showing the arrangement of a source holder designed for ease of positioning. The unit uses a liquid moderator $\left(\mathrm{H}_{2} \mathrm{O}\right)$ which can be removed for positioning.

- Figure 5: Sketch of shield for testing newtron shielding configurations and beam extraction geometries.

Figure 6: Radiograph density vs. exposure for various imaging techniques:

Figure 7: Arrangement and identification of test objects on the image quality indicator.

Figure 8: Comparison of radiographs made with two different LiF-ZnS scintillators.

Figure 9: Comparison of radiographs made with a $\mathrm{Gd}_{2} \mathrm{O}_{2} \mathrm{~S}: \mathrm{Tb}$ using two different films. 
FIGURE CAPTIONS (Cont'd)

Figure 10: Comparison of radiographs using a 2 mil gadolinium foil with different films.

Figure 11:. Comparison of radiographs taken with and without fiber optics face plates.

Figure 12: Neutron radiograph made with a europium metal foil in a flux of $7.8 \times 10^{2} \mathrm{n} / \mathrm{cm}^{2}-\mathrm{sec}$. 


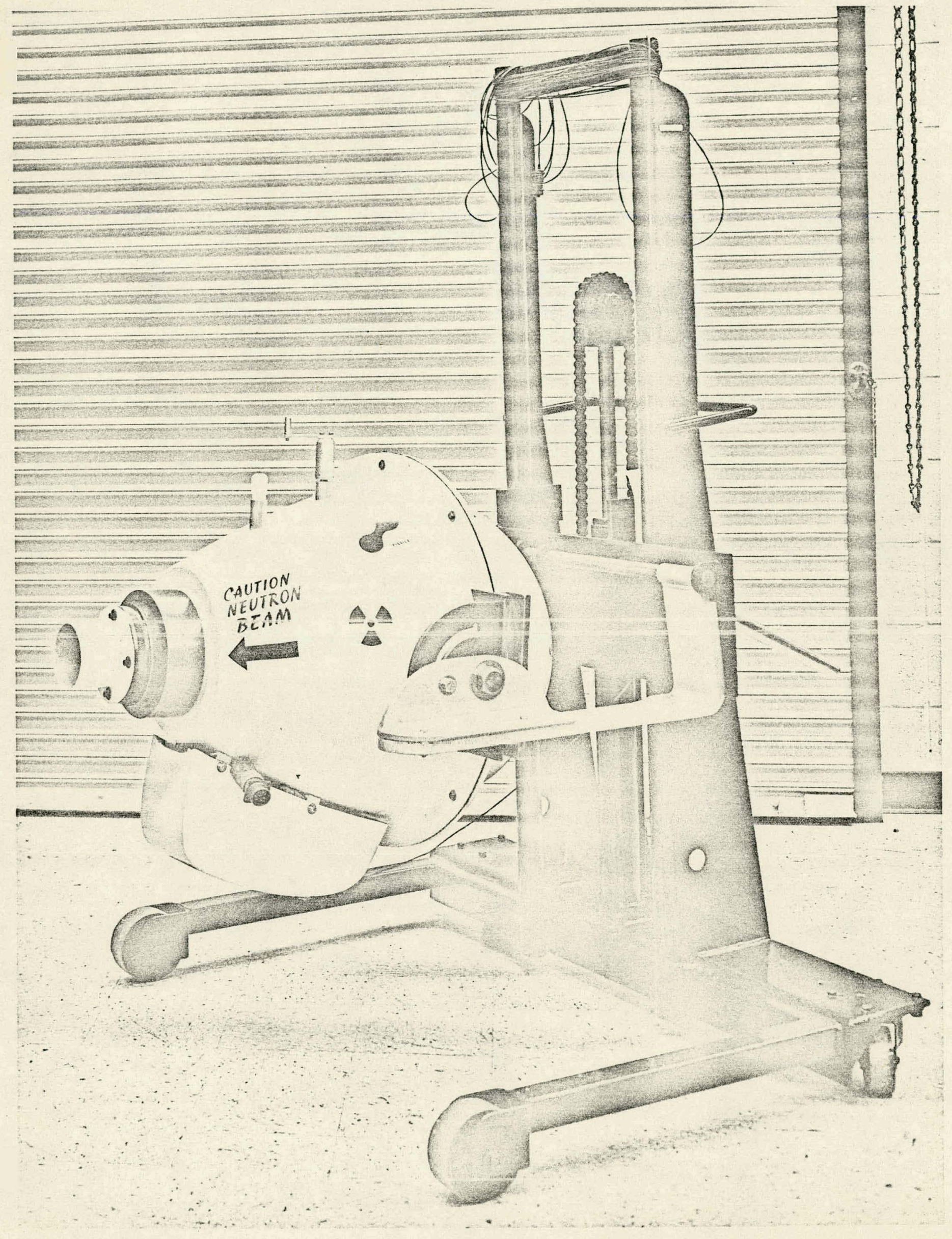




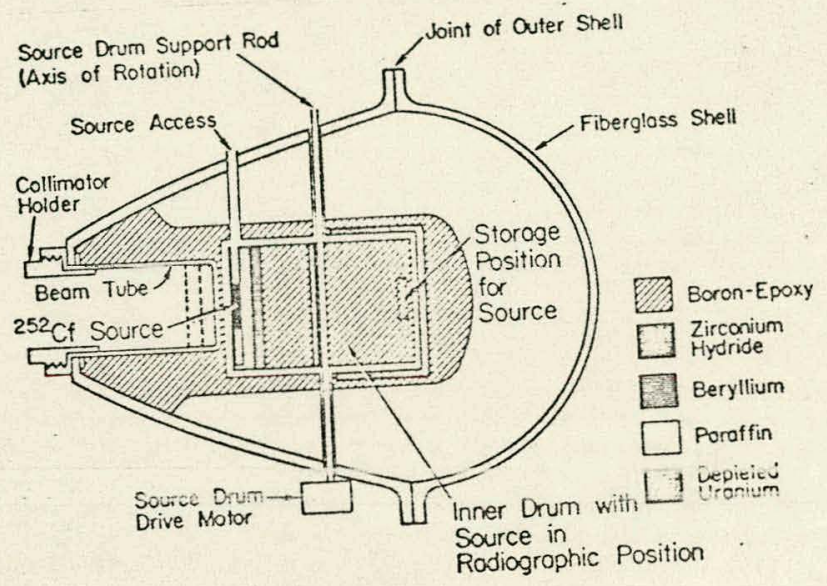




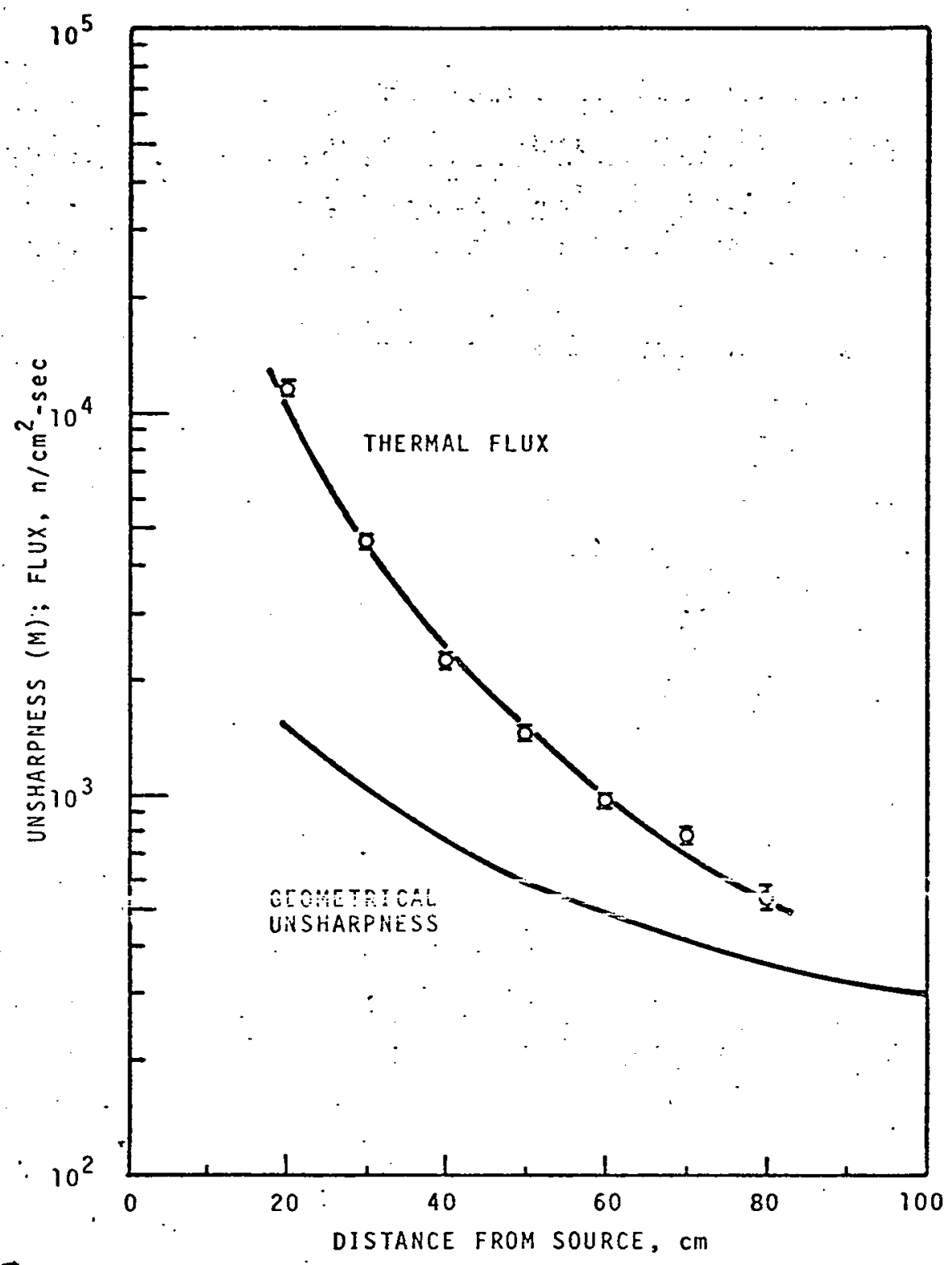

FIGURE 4. Thermal Flux and Calculated Geometrical Unsharpness for the Radiography Beam from NC-1. Operation with paraffin moderator and 0.1 in. lead gamma filter. 

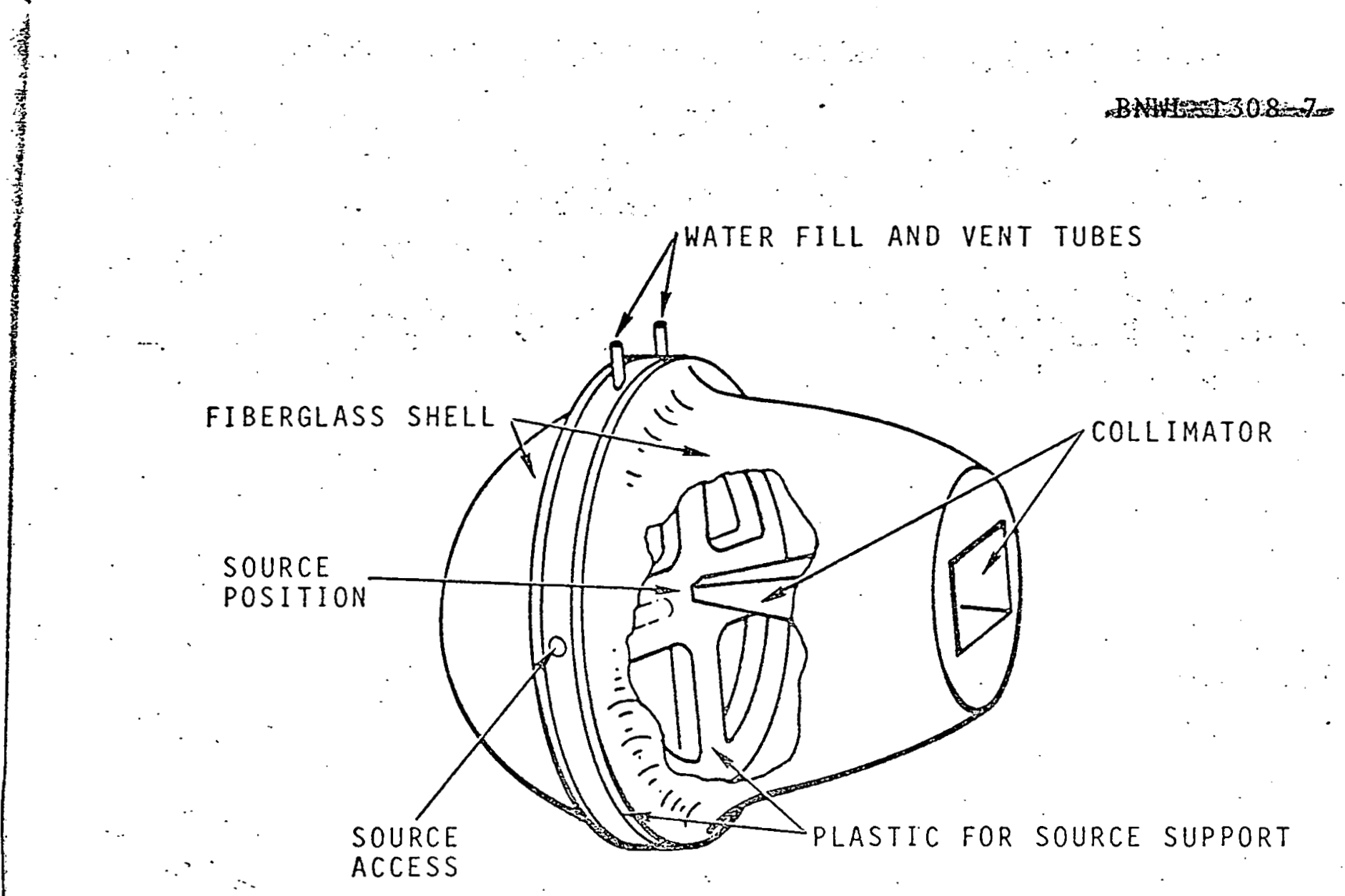

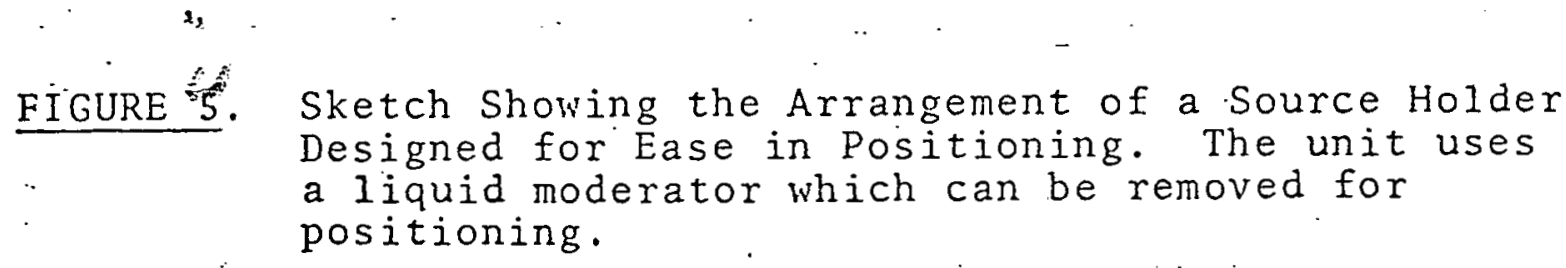




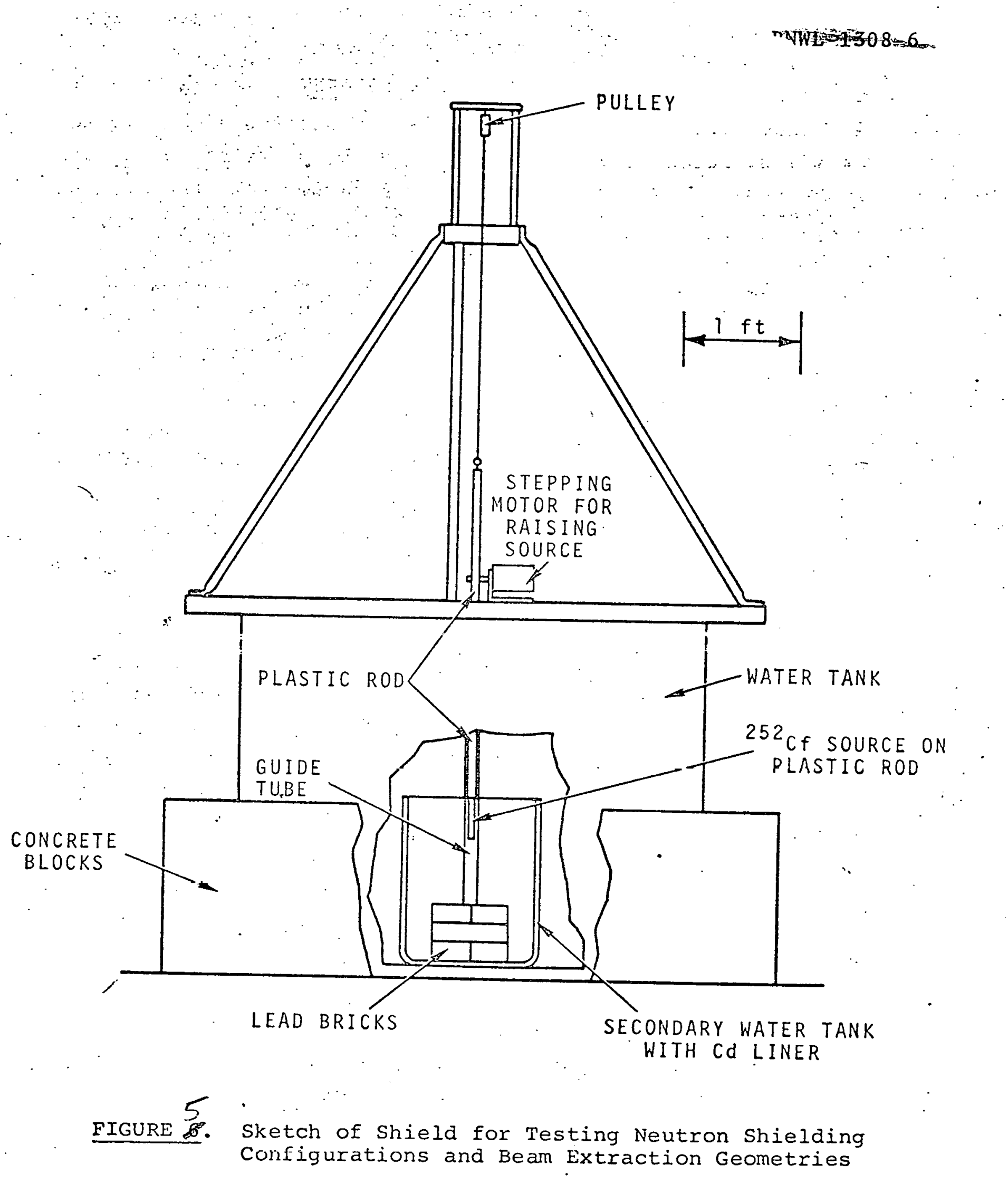




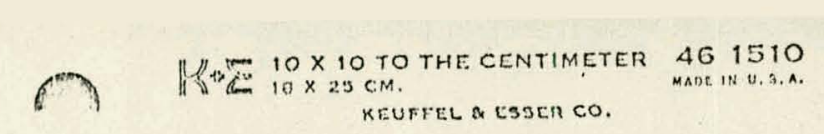

00

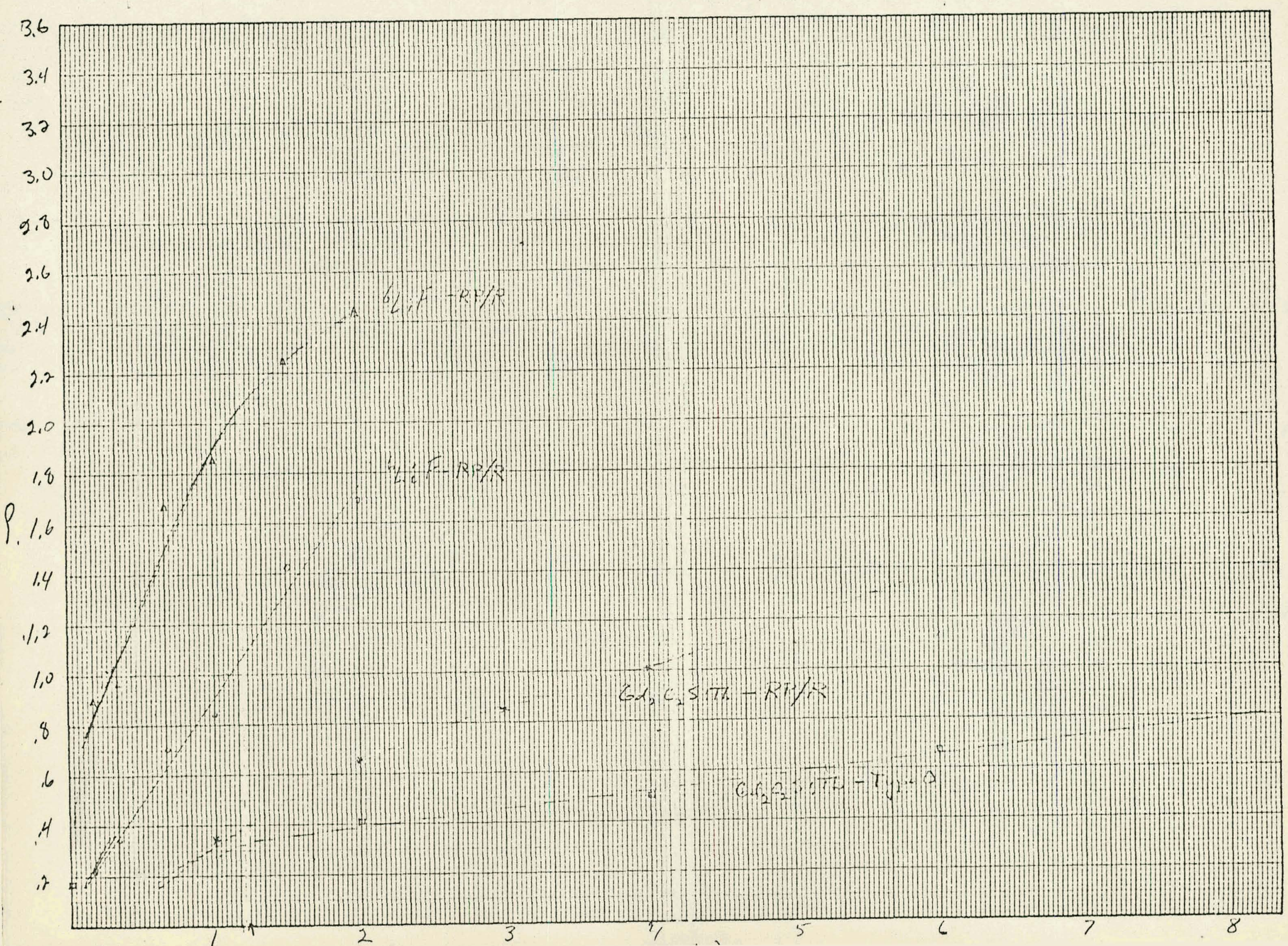




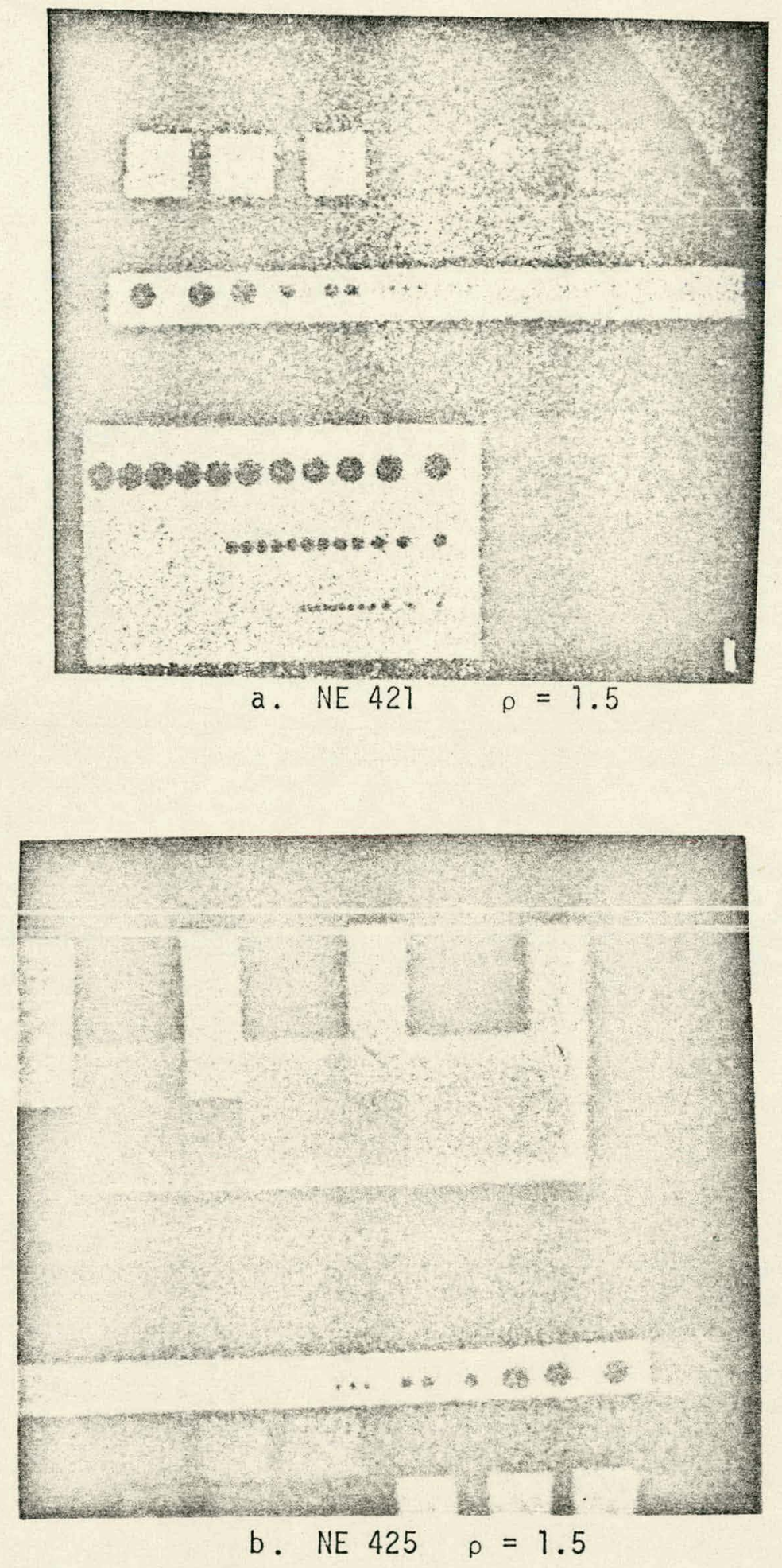

Comparison of radiographs made with two different LiF-ZnS scintillators. (F-8) 


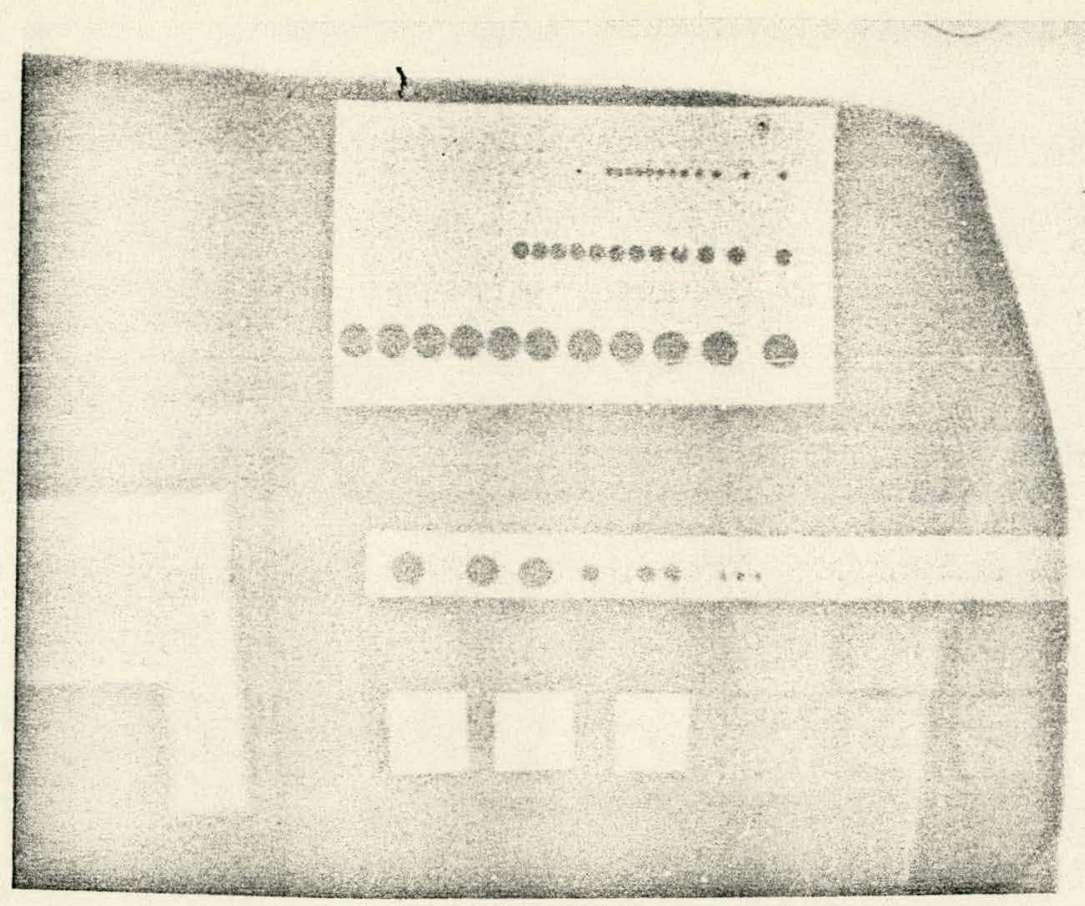

a. Type RP/R film $\rho=1.5$

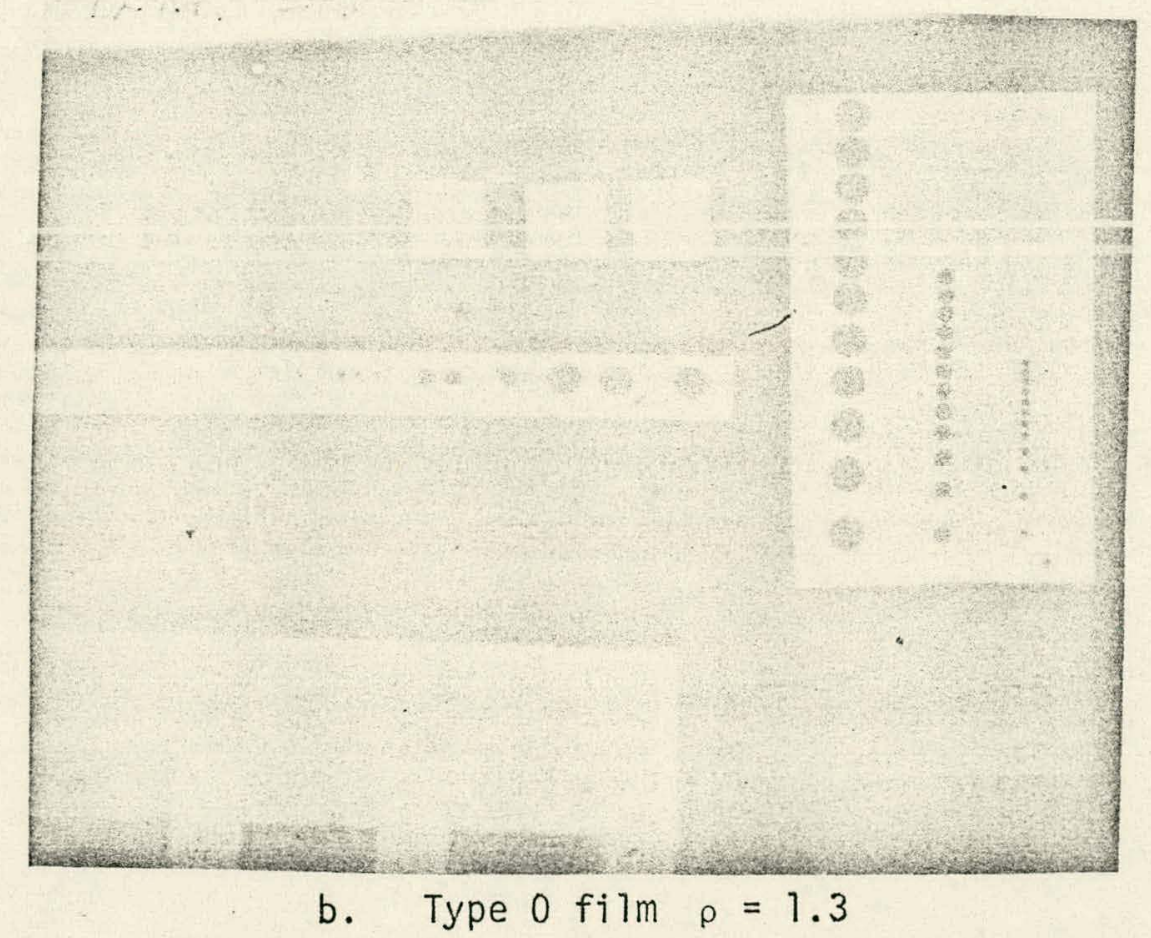

Comparison of radiographs made with a $\mathrm{Gd}_{2} \mathrm{O}_{2} \mathrm{~S}: \mathrm{Tb}$ using two different films (F-g) 


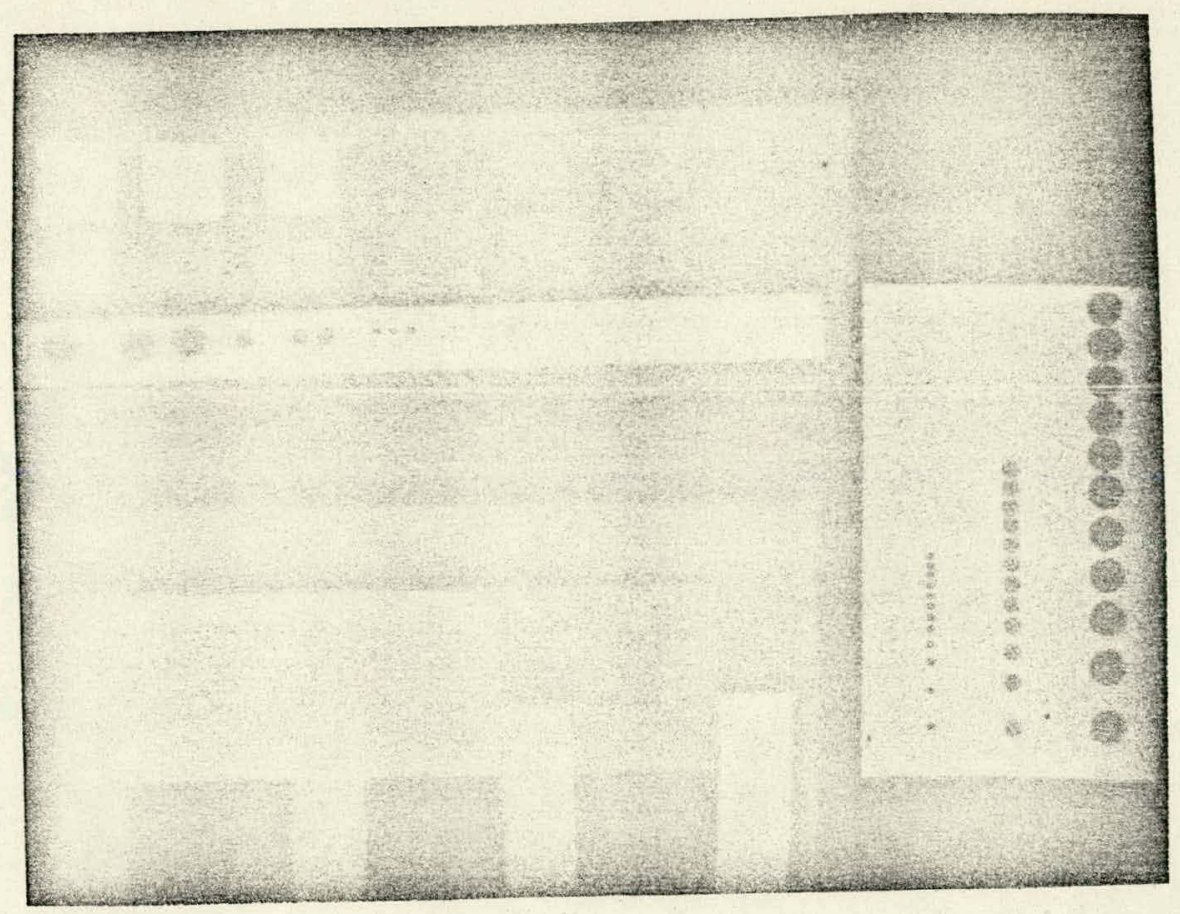

a. Type RP/R film $\rho=1.5$

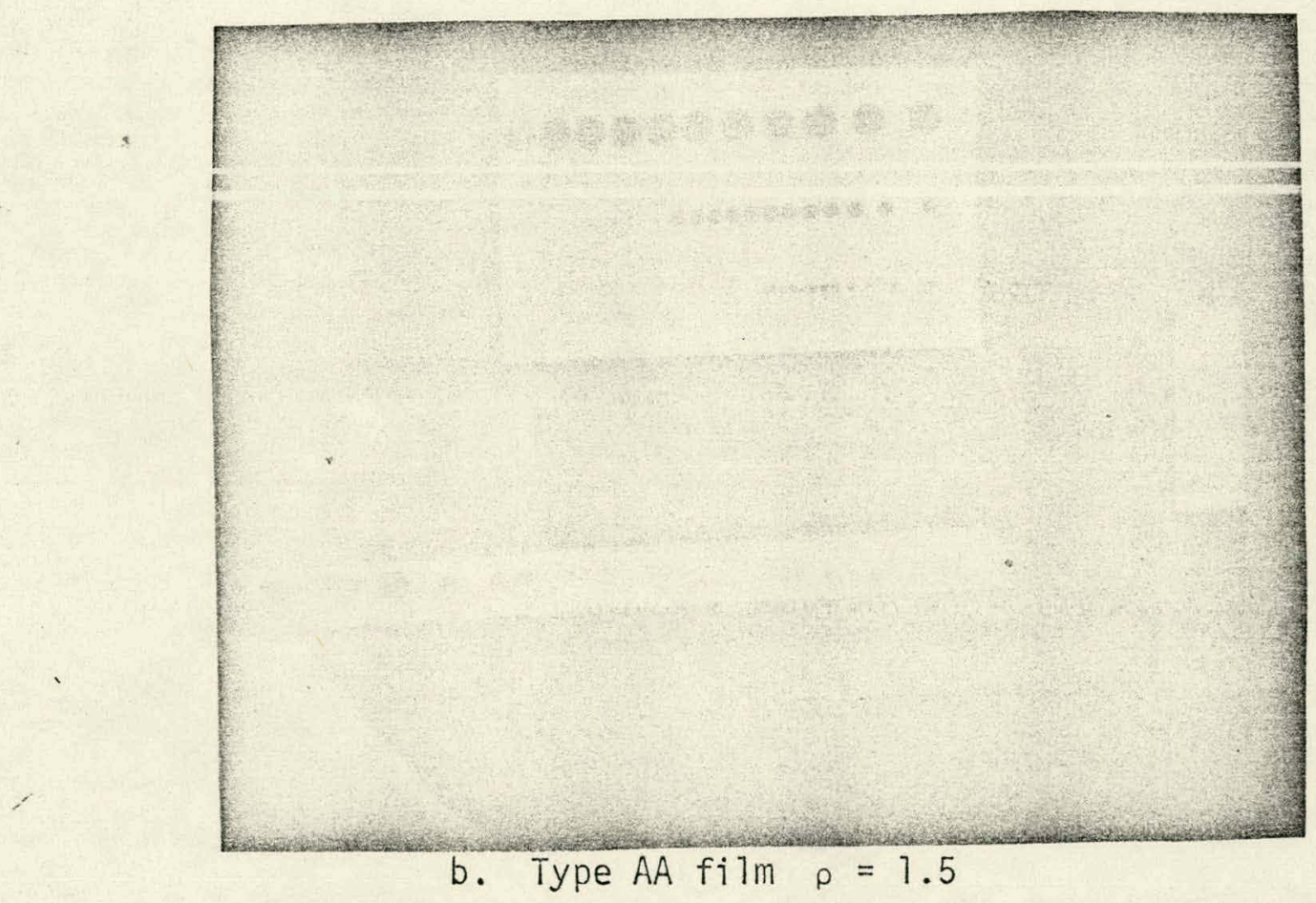

Comparison of radiographs using a 2 mil gadolinium foil with different films. (F-10) 


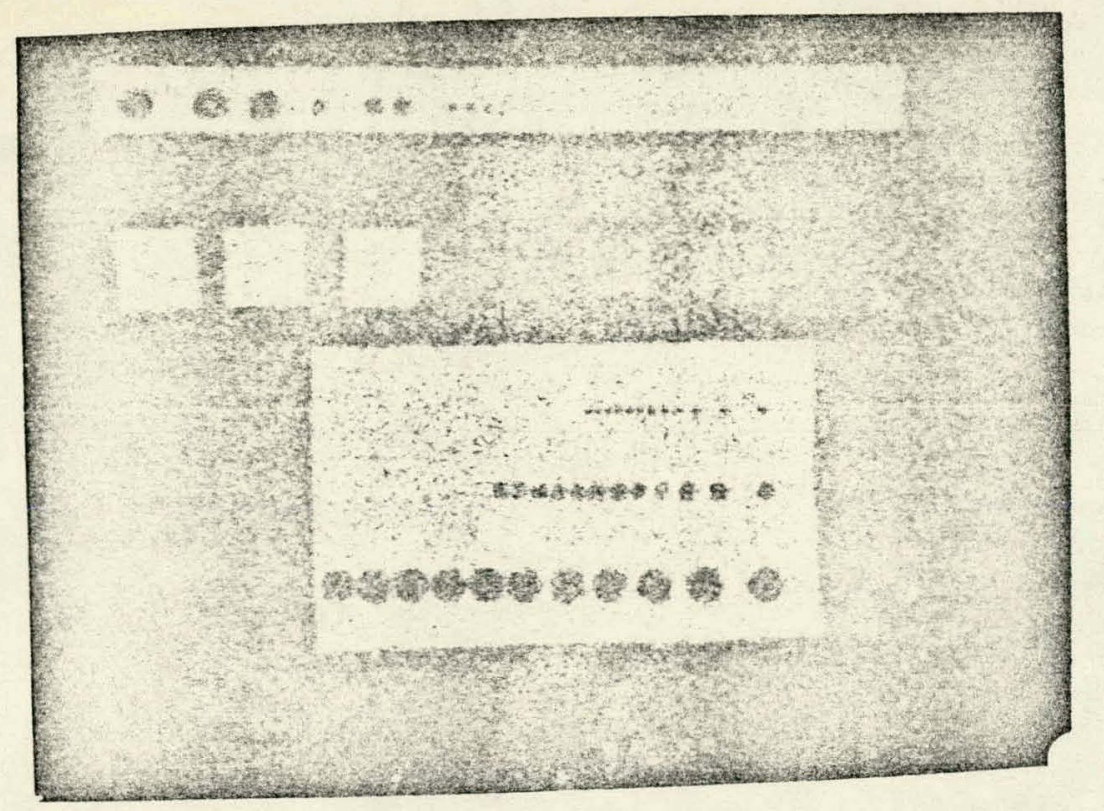

Scintillator Only

$\rho=1.5$

Time $=42$ minutes

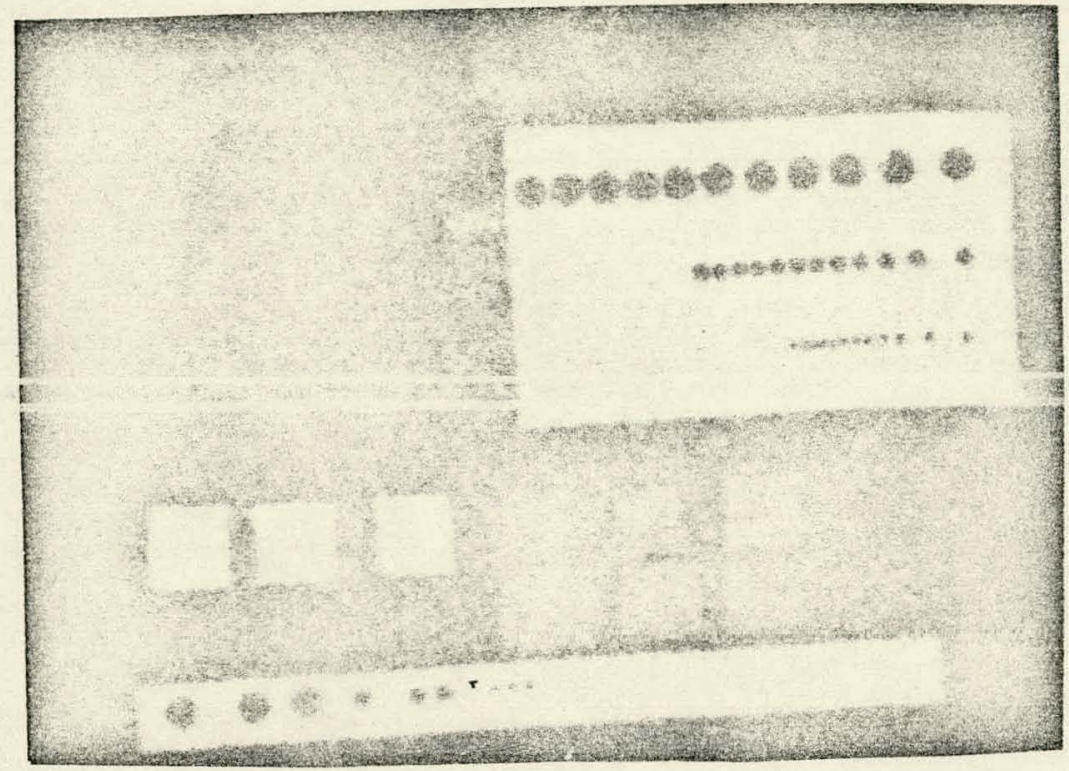

Scintillator plus large area fiber optics face plate with $10 \mu$ fibers

$\rho=1.5$

Time $=63$ minutes

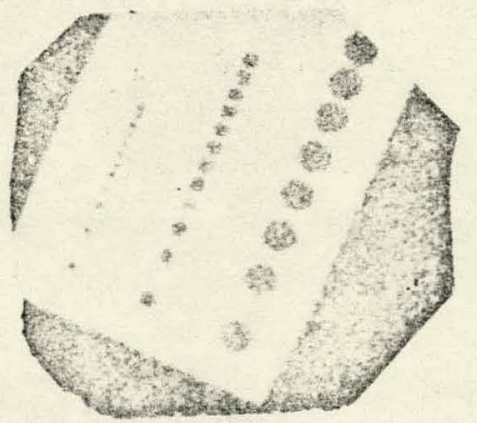

Scintillator plus small area fiber optics face plate with $5.5 \mu$ fibers. $\rho=1,3$

Time $=180$ minutes

Comparison of radiographs taken with and without fiber optics face plates. (F-11) 